论 文

\title{
青藏高原㒸塘中部中奥陶世变质堆晶辉长岩锆石 SHRIMP年代学及Hf同位素特征
}

\author{
翟庆国 ${ }^{(1 *} ，$ 王军 ${ }^{1}$ ，李才 ${ }^{2}$ ，苏犁 ${ }^{3}$ \\ (1) 中国地质科学院地质研究所, 北京 100037 ; \\ (2) 吉林大学地球科学学院, 长春 130061 ; \\ (3) 中国地质大学地学实验中心及地质过程与矿产资源重点实验室, 北京 100083 \\ *E-mail: zhaiqingguo@ 126.com
}

收稿日期: 2009-07-10; 接受日期: 2009-11-06

国家自然科学基金项目(批准号: 40872146, 40672147)、中国地质调查局(批准号: 1212010561605, 1212010911070)和中国地质科学院地质 研究所基本科研业务费项目(编号: J0910)资助

摘要藏北㒸塘桃形湖地区出露有一套变质基性岩, 主要岩石类型有变质超基性岩、变质 堆晶辉长岩、变质辉长岩(辉绿岩)、变质玄武岩和斜长花岗岩等, 局部可见有残留的堆晶(层 状)结构. 变质堆晶辉长岩的锆石 SHRIMP 定年和 Hf 同位素研究表明其时代为(467 44$) \mathrm{Ma}$, 这是目前㒸塘地区时代最老、最可靠的岩浆岩年龄. 变质堆晶辉长岩锆石 ${ }^{176} \mathrm{Hf} /{ }^{177} \mathrm{Hf}$ 比值介 于 $0.282615 \sim 0.282657$ 之间, $\varepsilon_{\mathrm{Hf}}(t)$ 加权平均值为 $5.02 \pm 0.28$, 反映其岩浆源区为亏损型地幔. 变 质基性岩地球化学特征与大洋中脊玄武岩类似, 它很可能是古洋壳的残片. 桃形湖变质基性 岩代表㒸塘中央隆起地区早古生代蛇绿岩残片.

关键词

姜塘

堆晶辉长岩

SHRIMP 定年

Hf 同位素
芫塘地处青藏高原的北部, 夹持于班公湖-怒江 缝合带和金沙江缝合带之间, 龙木错-双湖缝合带从 中间通过(图 1), 把㒸塘分割为南北两个地块一一芫 南地块和芫北地块 ${ }^{[1,2]}$. 芫塘南、北地层沉积建造和古 生物组合差别较大, 芫南地层具有亲冈瓦纳相的生 物组合和沉积特征, 㒸北具有亲欧亚大陆相的特征 ${ }^{[2]}$. 㒸塘地区蛇绿岩争论已近二十年 ${ }^{[1 \sim 6]}$, 近年来随着地 质调查和研究工作深入, 表明该地区存在典型的蛇

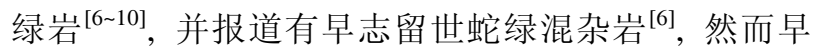
古生代地层出露较少. 㒸塘中央隆起地区出露有一 套浅变质岩石, 由于不含生物化石, 对其时代以及是 否存在早古生代以前的岩石仍存在争论 ${ }^{[10 ~ 12]}$. 总之,
芫塘处在冈瓦纳大陆和劳亚大陆的交汇部位, 是研 究古特提斯洋俯冲消减、大陆拼合、碰撞造山过程的 关键地区，但由于特殊的自然条件和交通条件，该地 区的研究程度很低, 尤其是蛇绿岩以及早古生代之 前的构造演化知之甚少, 尚需进一步深入研究.

桃形湖地区出露有一套浅变质的基性岩石, 主 要岩石类型有变质超基性岩、变质堆晶辉长岩、变质 辉长岩(辉绿岩)、变质玄武岩和斜长花岗岩等, 野外 可见残留的堆晶(层状)结构, 浅色和暗色条带明显, 这套岩石与芫塘中央隆起地区的浅变质岩共生 ${ }^{[11]}$, 它的形成与㒸塘地块早期构造演化密切相关. 本文 通过对具有残余层状结构的变质堆晶辉长岩的锆石 
SHRIMP 年代学和 Hf 同位素研究, 结合变质基性岩 地球化学资料, 探讨其地质意义, 并为㒸塘地区早古 生代构造演化的研究提供信息.

\section{1 地质概况}

桃形湖位于芫塘中部地区，改则县北约 $200 \mathrm{~km}$, 龙木错——双湖缝合带南侧. 该地区出露地层主要 有石炭系、二叠系和古近系(图 1). 石炭系主要为板 岩、片岩、千枚岩、石英岩、灰岩和基性火山岩等，局 部地方发育含砾板岩、冰海杂砾岩 ${ }^{[2]}$. 石炭系岩石变 质程度不高, 生物化石稀少, 《西藏自治区区域地质 志》将其时代定为前泥盆系 ${ }^{[11]}$, 王国芝和王成善 ${ }^{[12]}$ 将其划归元古代, 最近完成的 1:25 万区域地质调查 将它定为石炭系擦蒙组 ${ }^{1)}$, 然而对于该套“浅变质岩” 的时代仍然存在争论 ${ }^{[10]}$. 二叠纪出露较少, 主要分布 在冈玛错西南, 主要为含生物碎屑灰岩. 古近系康托 组红色砂岩、砾岩以角度不整合覆盖在石炭系、二叠 系之上. 桃形湖变质基性岩呈近东西向长条状出露
于桃形湖东南约 $10 \mathrm{~km}$ 处, 东西长约 $8 \mathrm{~km}$, 南北宽约 $2 \mathrm{~km}$, 周围覆盖有第四系沉积物, 与“浅变质岩”的关 系不太清楚. 岩石野外产状与果干加年山地区的类 似 ${ }^{[1,9]}$, 多呈岩块状或岩片状产出, 局部层状结构明 显, 可见后期辉(长)绿岩岩墙侵入其中, 并且岩石中 多发育斜长花岗岩(或斜长岩)呈脉状侵入或呈不规 则状产在堆晶辉长岩中(图 2,3). 变质基性岩成分主 要为阳起石、斜长石、䵢窝石和绿帘石, 局部地区含 有残留的辉石, 局部斜长花岗岩中还含有石榴石. 基 性岩变质程度不高且不均匀, 多经历了绿片岩相变 质作用, 辉石多转变为阳起石, 斜长石发生了䵢窝石 化, 但局部仍有辉石残留, 保留有辉长岩的结构, 变 形变质较强的地方可见定向排列的阳起石．堆晶岩 暗色部位多为辉石和角闪石(阳起石)，岩石的浅色部 位多为斜长石，并发生了䁫帘石化，局部还可见石英, 岩性转变为斜长岩或斜长花岗岩. 超基性岩变质变 形相对较强, 呈片状, 多数为蛇纹岩, 变质较深的部 位为角闪岩(主要成分为阳起石).

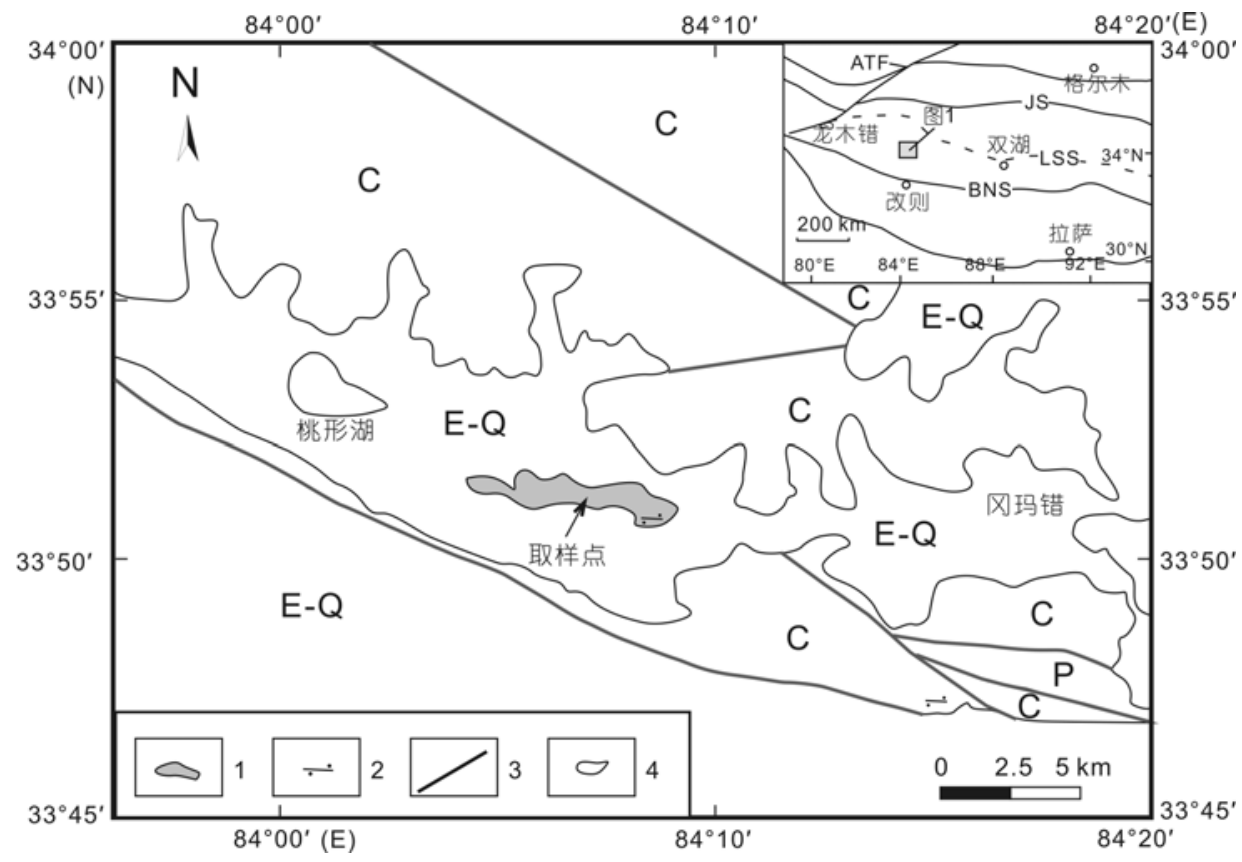

图 1 西藏羌塘中部桃形湖地区地质简图

1, 蛇绿混杂岩; 2, 蓝片岩; 3, 断层; 4, 湖泊; BNS, 班公湖-怒江缝合带; LSS, 龙木错-双湖缝合带; JS, 金沙江缝合带; ATF, 阿尔金断裂

1) 贵州地质调查研究院. 1:25 万丁固幅区域地质调查报告. 2005 


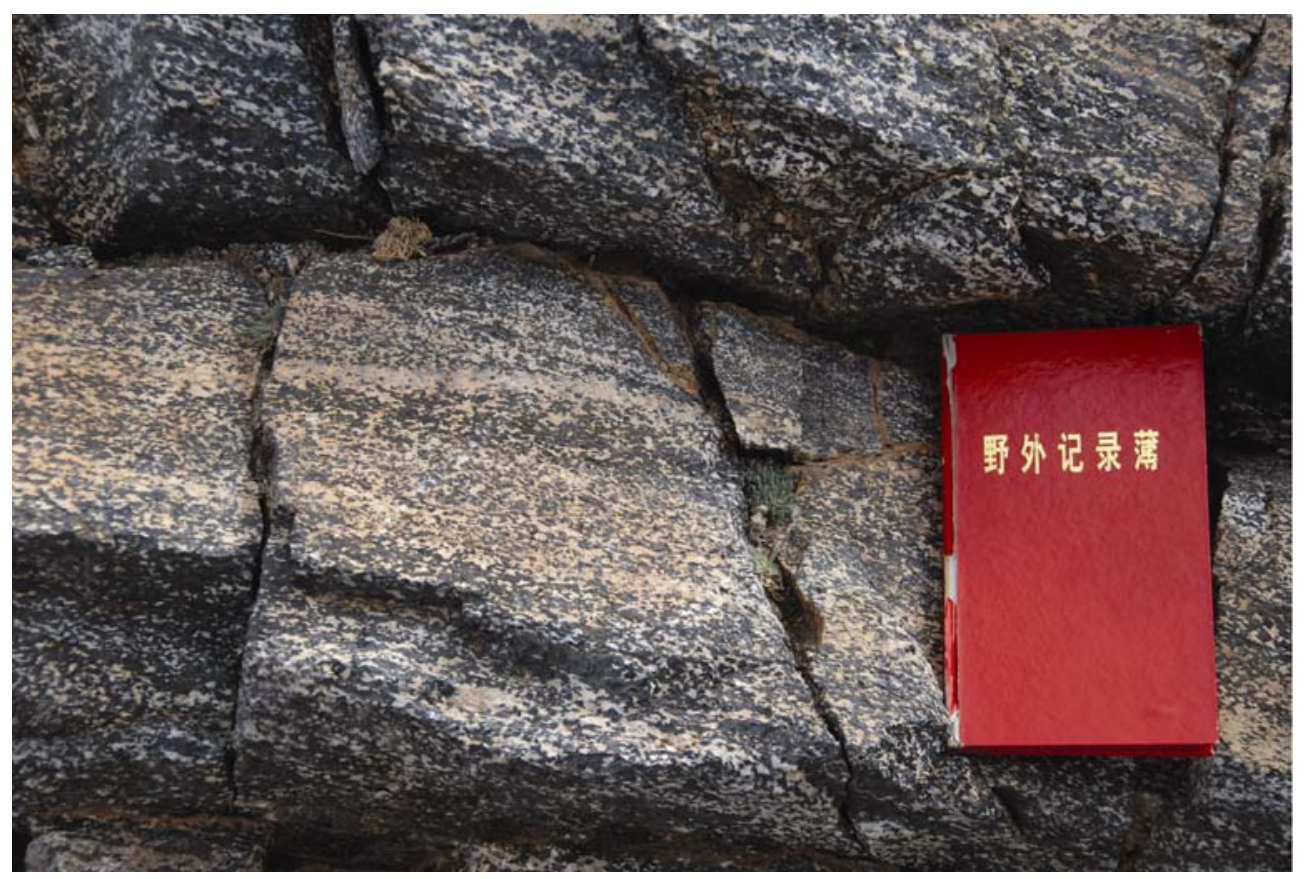

图 2 桃形湖变质堆晶辉长岩层状结构照片

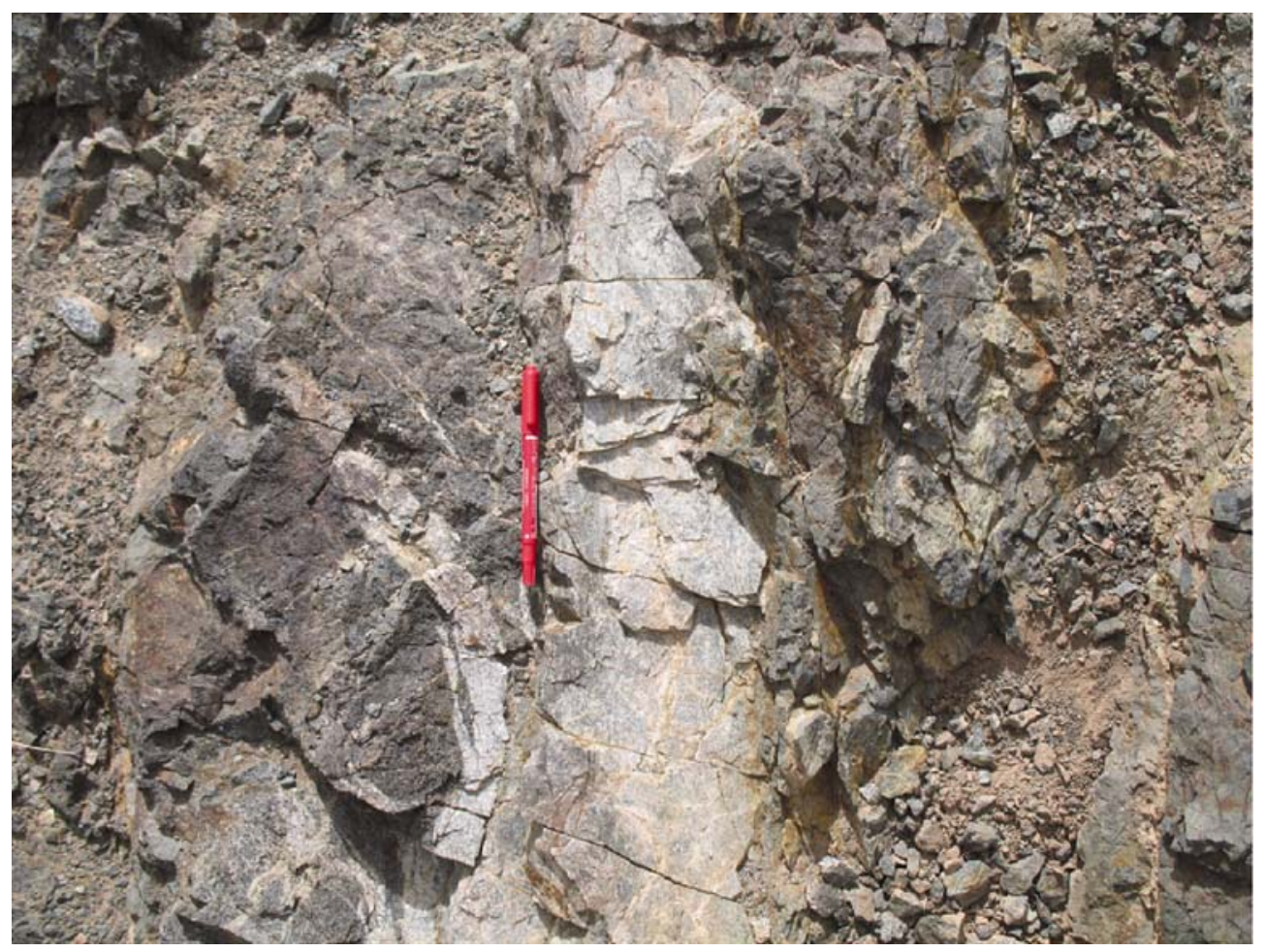

图 3 堆晶辉长岩(暗色)中斜长花岗岩脉体(浅色) 


\section{2 样品采集及测试}

本文锆石 SHRIMP 测年样品(Tao 02)采自桃形湖 东南约 $10 \mathrm{~km}$ 处, 采样位置见图 1. 样品选自颜色相 对较浅的浅变质堆晶辉长岩. 锆石挑选在河北地质 调查所实验室完成. 堆晶辉长岩锆石干净、透明, 多 为自形-半自形粒状、短柱状, 颗粒大小不一, 多在 200 300 $\mu \mathrm{m}$ 之间，长宽比多在 $1: 1 \sim 2: 1$ 之间. 在双目 镜下挑选出无裂隙、无包体的自形锆石颗粒, 将其与 标样置于环氧树脂中, 然后磨至约一半, 使内部暴露, 然后进行反射光、透射光和阴极发光显微照相. 锆石 $\mathrm{U}-\mathrm{Pb}$ 同位素分析在中国地质科学院地质研究所离子 探针中心用 SHRIMP II 型离子探针测定. 在分析过程 中, 应用标准锆石 TEM(417 Ma)进行元素间的分馏 校正, $\mathrm{Pb} / \mathrm{U}$ 校正公式采用 $\mathrm{Pb} / \mathrm{U}=\mathrm{A}(\mathrm{UO} / \mathrm{U})^{2[13]}$; 采用 澳大利亚国立大学地学院标准锆石 SL13(年龄: 572 Ma; U 含量: $238 \mu \mathrm{g} / \mathrm{g}$ ) 标定所测的锆石的 $\mathrm{U}, \mathrm{Th}$ 和 $\mathrm{Pb}$ 含量, 详细的 SHRIMP 分析方法和过程参阅文献[14]. 数据处理采用 Ludwig SQUID $1.0^{[15]}$ 和 ISOPLOT 程 序 ${ }^{[16]}$, 衰变常数使用 Steiger 等 ${ }^{[17]}$ 推荐值, 普通铅校 正使用直接测定 ${ }^{204} \mathrm{~Pb}$ 方法 ${ }^{[18]}$. 本文数据表 1 中所列 数据均为同一测点连续 5 次分析的平均值, 误差为 $1 \sigma$. 所有样品均采用 ${ }^{206} \mathrm{~Pb} /{ }^{238} \mathrm{U}$ 年龄, 加权平均值为 95\%的置信度.

样品锆石 $\mathrm{Hf}$ 同位素分析在中国科学院地质与地 球物理研究所完成. Hf 同位素分析在 Neptune 多接收 电感耦合等离子质谱仪(MC-ICP-MS)和 $193 \mathrm{~nm}$ 激光 取样系统上进行, 分析时激光束直径为 $60 \mu \mathrm{m}$ 激光剥 蚀时间约 $26 \mathrm{~s}$. 测定时用锆石国际标样 91500 锆石作
外标, 分析中所用激光脉冲速率为 $8 \sim 10 \mathrm{~Hz}$, 能量密 度为 $100 \mathrm{~mJ} / \mathrm{cm}^{2}$. 仪器的运行条件及详细的分析过程 参见 $\mathrm{Wu}$ 等 ${ }^{[19]}$. 本次实验测定过程中, 91500 锆石的 ${ }^{176} \mathrm{Hf} /{ }^{177} \mathrm{Hf}$ 的测定结果是 $0.282292 \pm 25$, 该值与目前 用溶液法获得的值在误差范围内一致 ${ }^{[20]}$. 主量元素 分析在中国科学院地质与地球物理研究所完成, 采 用 X-射线苂光光谱仪(XRF-1500)分析. 微量元素和 稀土元素在分析在中国地质大学(北京)地学实验中 心完成, 化学预处理采用两酸 $\left(\mathrm{HNO}_{3}+\mathrm{HF}\right)$ 高压反应 釜溶样方法, 分析仪器为 Agilent 7500a 型等离子质 谱仪, 实验室分析详细方法见文献[21].

\section{3 测试结果}

\section{1 锆石SHRIMP定年}

本文选择了 14 个具有代表性的锆石进行了分析, 测试结果见表 1. CL 图像显示, 锆石多具有补丁状、 弱环带、条带状或面状结构(图 4). 14 个分析点的 Th 含量变化于 52 337, U 变化于 78 501 $\mu \mathrm{g} / \mathrm{g}, \mathrm{Th}, \mathrm{U}$ 之 间具有正相关关系, $\mathrm{Th} / \mathrm{U}$ 比值在 0.49 0.92 之间, 为 典型的岩浆锆石 ${ }^{[22]}$. 获得的 14 个分析点 ${ }^{206} \mathrm{~Pb} /{ }^{238} \mathrm{U}$ 年 龄变化于 451.1 483.6 Ma 之间, 在谐和曲线上数据 点成群分布 (图 5), 加权平均年龄为 $(467 \pm 4) \mathrm{Ma}$ $(M S W D=1.5)$, 相当于中奥陶世, 代表堆晶辉长岩的 形成年龄.

\section{2 锆石 Hf同位素}

锆石 Hf 同位素分析点位置和 SHRIMP 测年点相

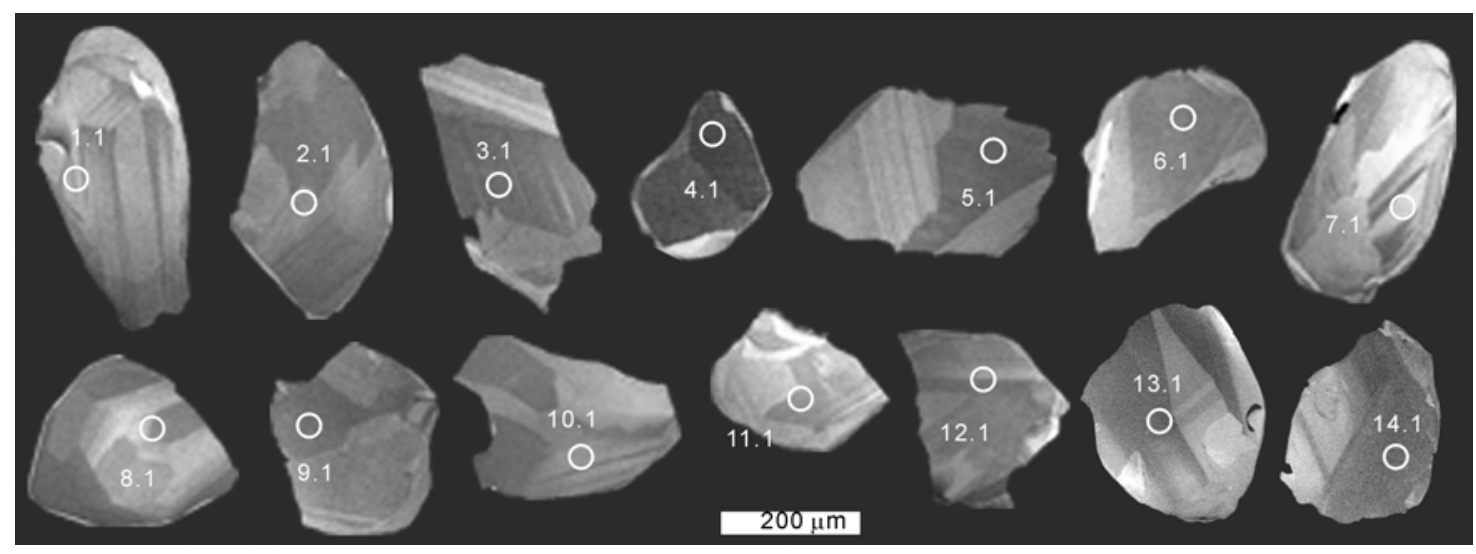

图 4 西藏芫塘中部桃形湖堆晶岩代表性锆石的锆石阴极发光照片 
表 1 藏北羌塘桃形湖堆晶辉长岩(Tao 02)锆石 SHRIMP U-Pb 年龄分析结果 ${ }^{\text {a) }}$

\begin{tabular}{|c|c|c|c|c|c|c|c|c|c|c|c|c|c|}
\hline 点号 & $\begin{array}{c}\mathrm{U} \\
(\mu \mathrm{g} / \mathrm{g})\end{array}$ & $\begin{array}{c}\mathrm{Th} \\
(\mu \mathrm{g} / \mathrm{g})\end{array}$ & $\begin{array}{l}{ }^{206} \mathrm{~Pb}^{*} \\
(\mu \mathrm{g} / \mathrm{g})\end{array}$ & $\begin{array}{l}{ }^{206} \mathrm{~Pb}_{\mathrm{c}} \\
(\mu \mathrm{g} / \mathrm{g})\end{array}$ & $\mathrm{Th} / \mathrm{U}$ & $\begin{array}{c}{ }^{207} \mathrm{~Pb}^{*} /{ }^{206} \mathrm{~Pb}^{*} \\
\pm 1 \sigma\end{array}$ & $\begin{array}{c}{ }^{207} \mathrm{~Pb}^{*} /{ }^{235} \mathrm{U} \\
\pm 1 \sigma\end{array}$ & $\begin{array}{c}{ }^{206} \mathrm{~Pb}^{*} /{ }^{238} \mathrm{U} \\
\pm 1 \sigma\end{array}$ & 误差 & $\begin{array}{l}{ }^{206} \mathrm{~Pb} /{ }^{238} \mathrm{U} \\
\pm 1 \sigma(\mathrm{Ma})\end{array}$ & $\begin{array}{l}{ }^{207} \mathrm{~Pb} /{ }^{206} \mathrm{~Pb} \\
\pm 1 \sigma(\mathrm{Ma})\end{array}$ & $\begin{array}{l}{ }^{208} \mathrm{~Pb} /{ }^{232} \mathrm{Th} \\
\pm 1 \sigma(\mathrm{Ma})\end{array}$ & $\begin{array}{c}\text { 不谐和度 } \\
(\%)\end{array}$ \\
\hline 1.1 & 78 & 55 & 4.97 & 1.30 & 0.73 & $0.0617 \pm 4.9$ & $0.622 \pm 5.3$ & $0.0731 \pm 2.0$ & 0.379 & $454.6 \pm 8.9$ & $664 \pm 110$ & $469 \pm 20$ & 32 \\
\hline 2.1 & 215 & 170 & 14.1 & 0.94 & 0.82 & $0.0557 \pm 3.4$ & $0.582 \pm 3.8$ & $0.0758 \pm 1.7$ & 0.446 & $470.9 \pm 7.6$ & $440 \pm 75$ & $443 \pm 13$ & -7 \\
\hline 3.1 & 118 & 98 & 7.57 & 0.66 & 0.86 & $0.0583 \pm 4.3$ & $0.595 \pm 4.6$ & $0.0740 \pm 1.8$ & 0.379 & $460.3 \pm 7.8$ & $540 \pm 93$ & $440 \pm 17$ & 15 \\
\hline 4.1 & 501 & 337 & 33.6 & 0.67 & 0.69 & $0.0550 \pm 1.9$ & $0.588 \pm 2.6$ & $0.0775 \pm 1.8$ & 0.673 & $481.2 \pm 8.2$ & $413 \pm 43$ & $440 \pm 11$ & -17 \\
\hline 5.1 & 128 & 112 & 8.55 & 1.79 & 0.91 & $0.0524 \pm 8.2$ & $0.553 \pm 8.4$ & $0.0764 \pm 1.8$ & 0.210 & $474.8 \pm 8.1$ & $305 \pm 190$ & $383 \pm 18$ & -56 \\
\hline 6.1 & 126 & 88 & 8.06 & 1.42 & 0.72 & $0.0562 \pm 6.3$ & $0.567 \pm 6.8$ & $0.0731 \pm 2.4$ & 0.350 & $455 \pm 10$ & $460 \pm 140$ & $383 \pm 22$ & 1 \\
\hline 7.1 & 152 & 102 & 9.61 & 1.68 & 0.70 & $0.0563 \pm 5.3$ & $0.563 \pm 5.6$ & $0.0725 \pm 1.8$ & 0.314 & $451.2 \pm 7.6$ & $464 \pm 120$ & $416 \pm 17$ & 3 \\
\hline 8.1 & 142 & 121 & 9.64 & 1.39 & 0.88 & $0.0581 \pm 5.2$ & $0.624 \pm 5.5$ & $0.0779 \pm 1.7$ & 0.313 & $483.6 \pm 8.1$ & $532 \pm 110$ & $435 \pm 30$ & 9 \\
\hline 9.1 & 117 & 104 & 7.57 & 1.24 & 0.92 & $0.0564 \pm 4.6$ & $0.580 \pm 4.9$ & $0.0746 \pm 1.8$ & 0.368 & $463.6 \pm 8.1$ & $468 \pm 100$ & $393 \pm 17$ & 1 \\
\hline 10.1 & 95 & 52 & 6.27 & 2.06 & 0.56 & $0.0502 \pm 7.6$ & $0.520 \pm 7.8$ & $0.0752 \pm 1.8$ & 0.234 & $467.6 \pm 8.2$ & $202 \pm 180$ & $452 \pm 29$ & -131 \\
\hline 11.1 & 101 & 88 & 6.83 & 2.24 & 0.91 & $0.0551 \pm 7.0$ & $0.587 \pm 7.3$ & $0.0772 \pm 1.9$ & 0.256 & $479.2 \pm 8.6$ & $418 \pm 160$ & $494 \pm 23$ & -15 \\
\hline 12.1 & 109 & 52 & 7.15 & 2.34 & 0.49 & $0.0518 \pm 7.1$ & $0.534 \pm 7.3$ & $0.0747 \pm 1.8$ & 0.246 & $464.7 \pm 8.0$ & $276 \pm 160$ & $417 \pm 32$ & -69 \\
\hline 13.1 & 121 & 102 & 7.80 & 1.44 & 0.87 & $0.0535 \pm 5.4$ & $0.545 \pm 5.7$ & $0.0739 \pm 1.8$ & 0.309 & $459.5 \pm 7.8$ & $351 \pm 120$ & $456 \pm 18$ & -31 \\
\hline 14.1 & 115 & 102 & 7.61 & 2.43 & 0.91 & $0.0476 \pm 8.4$ & $0.491 \pm 8.6$ & $0.0749 \pm 1.8$ & 0.209 & $465.4 \pm 8.1$ & $78 \pm 200$ & $426 \pm 21$ & -496 \\
\hline
\end{tabular}

a) ${ }^{206} \mathrm{~Pb}_{\mathrm{c}}$ 为普通铅; ${ }^{206} \mathrm{~Pb}^{*}$ 为放射性成因铅

表 2 藏北㒸塘桃形湖堆晶辉长岩(Tao 02)锆石 Hf 同位素组成

\begin{tabular}{|c|c|c|c|c|c|c|c|c|c|c|}
\hline 点号 & $\begin{array}{l}{ }^{206} \mathrm{~Pb} /{ }^{238} \mathrm{U} \\
\text { 年龄 }(\mathrm{Ma})\end{array}$ & ${ }^{176} \mathrm{Yb} /{ }^{177} \mathrm{Hf}$ & ${ }^{176} \mathrm{Lu} /{ }^{177} \mathrm{Hf}$ & ${ }^{176} \mathrm{Hf} /{ }^{177} \mathrm{Hf}$ & $2 \sigma$ & $\varepsilon_{\mathrm{Hf}}(0)$ & $\varepsilon_{\mathrm{Hf}}(t)$ & $2 \sigma$ & $T_{\mathrm{DM}}(\mathrm{Ma})$ & $f_{\mathrm{Lu} / \mathrm{Hf}}$ \\
\hline 01 & 455 & 0.014407 & 0.000466 & 0.282631 & 0.000023 & -5.0 & 4.9 & 0.8 & 868 & -0.99 \\
\hline 02 & 471 & 0.016823 & 0.000552 & 0.282635 & 0.000016 & -4.8 & 5.3 & 0.6 & 864 & -0.98 \\
\hline 03 & 460 & 0.015748 & 0.000513 & 0.282626 & 0.000016 & -5.2 & 4.8 & 0.6 & 875 & -0.98 \\
\hline 04 & 481 & 0.028187 & 0.000952 & 0.282624 & 0.000013 & -5.2 & 5.0 & 0.5 & 889 & -0.97 \\
\hline 05 & 475 & 0.019728 & 0.000632 & 0.282617 & 0.000019 & -5.5 & 4.8 & 0.7 & 892 & -0.98 \\
\hline 06 & 455 & 0.011674 & 0.000388 & 0.282619 & 0.000016 & -5.4 & 4.5 & 0.6 & 883 & -0.99 \\
\hline 07 & 451 & 0.014099 & 0.000475 & 0.282630 & 0.000013 & -5.0 & 4.8 & 0.5 & 869 & -0.99 \\
\hline 08 & 484 & 0.014912 & 0.000491 & 0.282615 & 0.000017 & -5.6 & 4.9 & 0.6 & 891 & -0.99 \\
\hline 09 & 464 & 0.020040 & 0.000641 & 0.282624 & 0.000016 & -5.2 & 4.8 & 0.6 & 882 & -0.98 \\
\hline 10 & 468 & 0.016163 & 0.000537 & 0.282637 & 0.000014 & -4.8 & 5.4 & 0.5 & 861 & -0.98 \\
\hline 11 & 479 & 0.019030 & 0.000608 & 0.282634 & 0.000017 & -4.9 & 5.5 & 0.6 & 867 & -0.98 \\
\hline 12 & 465 & 0.011532 & 0.000391 & 0.282633 & 0.000012 & -4.9 & 5.2 & 0.4 & 863 & -0.99 \\
\hline 13 & 460 & 0.013910 & 0.000465 & 0.282622 & 0.000012 & -5.3 & 4.7 & 0.4 & 881 & -0.99 \\
\hline 14 & 465 & 0.021728 & 0.000706 & 0.282657 & 0.000017 & -4.1 & 5.9 & 0.6 & 837 & -0.98 \\
\hline
\end{tabular}

对应, 分析结果见表 2. Tao 02 样品锆石 ${ }^{176} \mathrm{Hf} /{ }^{177} \mathrm{Hf}$ 比值较低，分布于 $0.282615 \sim 0.282657$ 之间，根据每 个锆石的 SHRIMP 年龄计算, $\varepsilon_{\mathrm{Hf}}(t)$ 值在 4.5 5.9 之间, 加权平均值为 $5.02 \pm 0.28, \mathrm{Hf}$ 模式年龄 $\left(T_{\mathrm{DM}}\right)$ 变化范围 为 837 892 Ma, 平均年龄为 $873 \mathrm{Ma}$.

\section{4 地球化学特征}

桃形湖变质基性岩地球化学分析表明(表 3 ), $\mathrm{SiO}_{2}$ 含量多在 $50 \%$ 左右, 变质堆晶岩浅色部位 $(\mathrm{TaO}$ 05 , 斜长花岗岩 $) \mathrm{SiO}_{2}$ 含量较高, 可达 $74.35 \%, \mathrm{TiO}_{2}$ 含 量较低(多小于 $0.7 \%$ ), 在硅碱图上(图略)样品均位于
亚碱性玄武岩系列的区域，具有拉斑玄武岩的特征. 变质堆晶岩由暗色部位到浅色部位, 斜长石含量逐 渐增加, 局部含有少量石英, 岩性转变为斜长花岗岩, $\mathrm{SiO}_{2}$ 含量也相对较高. 岩石中 $\mathrm{SiO}_{2}$ 与其它主量元素 相关性明显, 随着 $\mathrm{SiO}_{2}$ 增加, $\mathrm{TiO}_{2}, \mathrm{Fe}_{2} \mathrm{O}_{3}{ }^{\mathrm{T}}, \mathrm{Al}_{2} \mathrm{O}_{3}$, $\mathrm{MgO}$ 和 $\mathrm{CaO}$ 逐渐减少, 表明这些岩石之间具有成因 关系, 而且结晶分离起着重要作用. 稀土元素总量较 低( $\Sigma R E E$ 在 25.23 45.82 $\mu \mathrm{g} / \mathrm{g}$ 之间), 稀土元素球粒陨 石标准化曲线为以平坦型为主(图 6), 具有与大洋中 脊玄武岩 $(\mathrm{N}-\mathrm{MORB})$ 类似的特征, 与果干加年山地区 的变质堆晶岩类似 ${ }^{[9]}$. 变质堆晶岩浅色部位(斜长花 岗岩 Tao 05)具有明显的 Eu 正异常，反映出岩浆结晶 


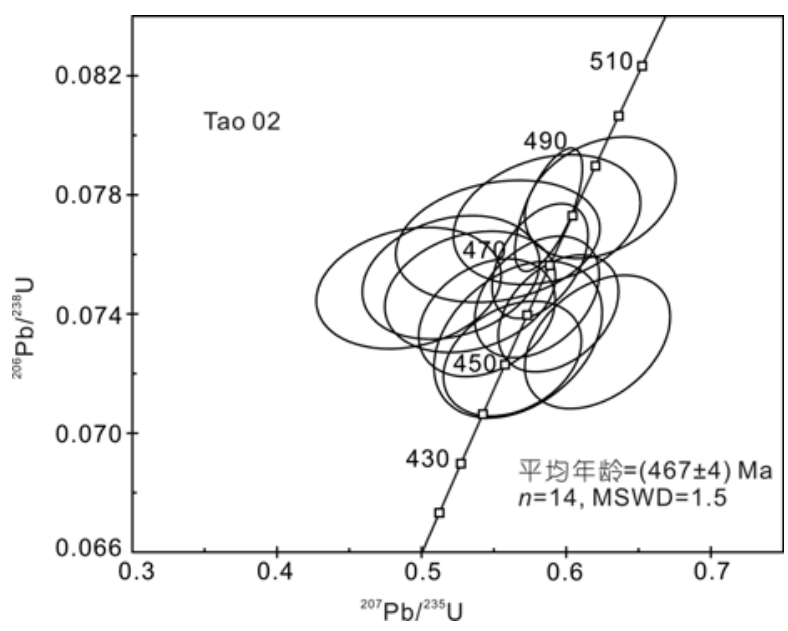

图 5 西藏芫塘中部桃形湖堆晶岩锆石 SHRIMP U-Pb 年龄 谐和图

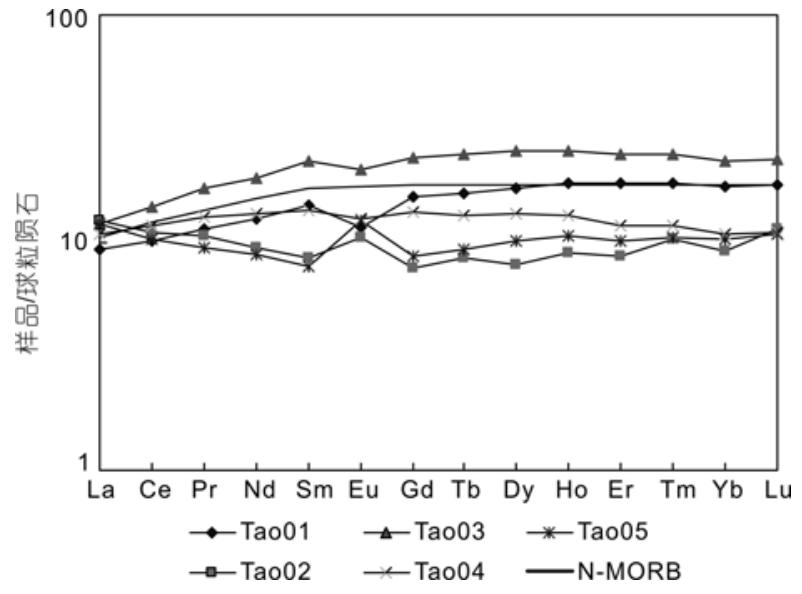

图 6 藏北差塘桃形湖地区变质基性岩稀土配分曲线 球粒陨石和 N-MORB 数据见文献[23]

表 3 藏北㒸塘桃形湖变质基性岩主量 $(\%)$ 、微量元素 $(\mu \mathrm{g} / \mathrm{g})$ 分析结果

\begin{tabular}{|c|c|c|c|c|c|c|c|c|c|c|c|}
\hline 样品号 & Tao 01 & Taо 02 & Тао 03 & Taо 04 & Tao 05 & 样品号 & Tao 01 & Taо 02 & Тао 03 & Taо 04 & Tao 05 \\
\hline 岩石名称 & $\begin{array}{c}\text { 浅色 } \\
\text { 辉长岩 }\end{array}$ & $\begin{array}{c}\text { 浅色 } \\
\text { 辉长岩 }\end{array}$ & 辉长岩 & $\begin{array}{c}\text { 浅色 } \\
\text { 辉长岩 }\end{array}$ & $\begin{array}{c}\text { 斜长 } \\
\text { 花岗石 }\end{array}$ & 岩石名称 & $\begin{array}{c}\text { 浅色 } \\
\text { 辉长岩 }\end{array}$ & $\begin{array}{c}\text { 浅色 } \\
\text { 辉长岩 }\end{array}$ & 辉长岩 & $\begin{array}{c}\text { 浅色 } \\
\text { 辉长岩 }\end{array}$ & $\begin{array}{c}\text { 斜长 } \\
\text { 花岗石 }\end{array}$ \\
\hline $\mathrm{SiO}_{2}$ & 55.16 & 54.39 & 50.04 & 57.22 & 74.35 & $(\mathrm{La} / \mathrm{Sm})_{\mathrm{N}}$ & 0.64 & 1.47 & 0.53 & 0.79 & 1.53 \\
\hline $\mathrm{TiO}_{2}$ & 0.71 & 0.6 & 1.36 & 0.55 & 0.36 & $\delta \mathrm{Eu}$ & 0.77 & 1.30 & 0.89 & 0.92 & 1.50 \\
\hline $\mathrm{Al}_{2} \mathrm{O}_{3}$ & 17.11 & 17.41 & 13.91 & 14.75 & 12.72 & $\mathrm{Li}$ & 5.526 & 5.430 & 9.057 & 6.266 & 2.527 \\
\hline $\mathrm{Fe}_{2} \mathrm{O}_{3}^{\mathrm{T}}$ & 10.65 & 11.14 & 11.41 & 9.95 & 3.88 & $\mathrm{Ti}$ & 4256.5 & 3597.0 & 8153.2 & 3297.3 & 2158.2 \\
\hline $\mathrm{MnO}$ & 0.22 & 0.25 & 0.18 & 0.16 & 0.11 & $\mathrm{~K}$ & 489.8 & 440.0 & 91.3 & 415.1 & 66.4 \\
\hline $\mathrm{MgO}$ & 4.25 & 4.32 & 7.61 & 4.87 & 0.55 & $\mathrm{Rb}$ & 7.420 & 4.334 & 0.517 & 9.471 & 0.970 \\
\hline $\mathrm{CaO}$ & 7.86 & 7.77 & 11.01 & 7.18 & 4.38 & $\mathrm{Sr}$ & 225.7 & 185.5 & 95.59 & 196.6 & 220.2 \\
\hline $\mathrm{Na}_{2} \mathrm{O}$ & 2.07 & 2.03 & 2.9 & 3.15 & 2.89 & $\mathrm{Y}$ & 26.79 & 12.07 & 36.64 & 18.85 & 15.79 \\
\hline $\mathrm{K}_{2} \mathrm{O}$ & 0.59 & 0.53 & 0.11 & 0.5 & 0.08 & $\mathrm{Zr}$ & 21.83 & 11.79 & 80.37 & 23.09 & 55.51 \\
\hline $\mathrm{P}_{2} \mathrm{O}_{5}$ & 0.08 & 0.08 & 0.11 & 0.11 & 0.08 & $\mathrm{Nb}$ & 1.387 & 1.599 & 2.168 & 1.338 & 0.885 \\
\hline LOI & 1.32 & 1.45 & 1.45 & 1.55 & 0.62 & $\mathrm{Cs}$ & 0.855 & 0.555 & 0.151 & 0.439 & 0.362 \\
\hline 总计 & 100.0 & 99.97 & 100.1 & 99.99 & 100.0 & $\mathrm{Ba}$ & 117.5 & 84.48 & 10.95 & 100.9 & 28.29 \\
\hline $\mathrm{La}$ & 2.229 & 2.982 & 2.874 & 2.593 & 2.872 & Hf & 0.756 & 0.446 & 2.337 & 0.918 & 1.540 \\
\hline $\mathrm{Ce}$ & 6.229 & 6.842 & 8.840 & 7.319 & 6.329 & $\mathrm{Ta}$ & 0.081 & 0.128 & 0.158 & 0.083 & 0.052 \\
\hline $\operatorname{Pr}$ & 1.094 & 1.015 & 1.637 & 1.231 & 0.901 & $\mathrm{~Pb}$ & 1.893 & 2.496 & 0.572 & 1.105 & 0.622 \\
\hline $\mathrm{Nd}$ & 5.952 & 4.429 & 8.998 & 6.206 & 4.129 & Th & 0.066 & 0.232 & 0.203 & 0.200 & 0.359 \\
\hline $\mathrm{Sm}$ & 2.249 & 1.312 & 3.473 & 2.119 & 1.213 & $\mathrm{U}$ & 0.044 & 0.061 & 0.071 & 0.057 & 0.053 \\
\hline $\mathrm{Eu}$ & 0.681 & 0.616 & 1.204 & 0.734 & 0.721 & $\mathrm{~V}$ & 213.9 & 206.3 & 379.1 & 186.4 & 14.94 \\
\hline $\mathrm{Gd}$ & 3.274 & 1.595 & 4.876 & 2.813 & 1.784 & $\mathrm{Cr}$ & 23.01 & 25.29 & 68.83 & 139.3 & 8.116 \\
\hline $\mathrm{Tb}$ & 0.619 & 0.319 & 0.916 & 0.496 & 0.348 & $\mathrm{Mn}$ & 1585.1 & 1757.7 & 1419.8 & 1165.9 & 835.2 \\
\hline Dy & 4.413 & 2.046 & 6.438 & 3.431 & 2.602 & $\mathrm{Co}$ & 25.80 & 25.92 & 43.47 & 23.18 & 3.524 \\
\hline Ho & 1.029 & 0.507 & 1.437 & 0.747 & 0.611 & $\mathrm{Ni}$ & 13.29 & 13.81 & 47.26 & 26.10 & 3.840 \\
\hline $\mathrm{Er}$ & 3.029 & 1.449 & 4.058 & 1.952 & 1.679 & $\mathrm{Cu}$ & 56.34 & 57.26 & 41.43 & 38.70 & 12.82 \\
\hline $\mathrm{Tm}$ & 0.463 & 0.262 & 0.619 & 0.302 & 0.267 & $\mathrm{Zn}$ & 80.18 & 76.58 & 102.1 & 84.98 & 20.56 \\
\hline $\mathrm{Yb}$ & 2.974 & 1.562 & 3.855 & 1.859 & 1.745 & $\mathrm{Be}$ & 0.340 & 0.435 & 0.359 & 0.414 & 0.369 \\
\hline $\mathrm{Lu}$ & 0.459 & 0.291 & 0.590 & 0.279 & 0.277 & $\mathrm{Sc}$ & 42.02 & 39.88 & 45.13 & 37.38 & 13.64 \\
\hline$\Sigma \mathrm{REE}$ & 34.69 & 25.23 & 49.82 & 32.08 & 25.48 & $\mathrm{Ga}$ & 15.12 & 14.64 & 16.53 & 13.55 & 11.13 \\
\hline$(\mathrm{La} / \mathrm{Yb})_{\mathrm{N}}$ & 0.54 & 1.37 & 0.53 & 1.00 & 1.18 & Mo & 0.151 & 0.252 & 0.199 & 0.257 & 0.250 \\
\hline
\end{tabular}


过程中斜长石堆积的特征, 而暗色部位(浅色辉长岩、 辉长岩)具有不同程度的 $\mathrm{Eu}$ 负异常, 与浅色部位具有 一定的互补性. 微量元素中 $\mathrm{Sr}$ 和 $\mathrm{Pb}$ 相对较富集, $\mathrm{Rb}$ 和 $\mathrm{Ba}$ 也有一定的富集性, $\mathrm{K}$ 具有不同程度亏损, 它们 可能是由于后期变质作用所致, $\mathrm{Ti}$ 具有明显的负异常, 说明岩石可能具有岛弧岩浆活动的亲缘性. 微量元 素原始地幔标准化蛛网图与 N-MORB 类似(图 7).

\section{5 讨论}

\section{1 变质基性岩时代}

桃形湖变质堆晶辉长岩锆石具有补丁状、弱环 带、条带状或面状结构, Th/U 比值在 0.49 0.92 之间, 与基性岩浆结晶的锆石类似, 进而说明其不会是地 壳物质混染形成的. 锆石 14 个分析点年龄在 451.1 483.6 Ma 之间, 加权平均年龄为 $(467 \pm 4) \mathrm{Ma}$, 代表变质基性岩岩浆结晶的时代. 最近, 翟庆国等 ${ }^{[9]}$ 在果干加年山地区发现了具有典型大洋中脊特征的 岩石组合, 并获得了 $(438 \pm 11) \mathrm{Ma}$ 变质堆晶岩锆石 SHRIMP 年龄 ${ }^{[6]}$, 认为该地区存在早志留世蛇绿混杂 岩. 桃形湖变质堆晶辉长岩时代为中奥陶世, 很可能 代表羌塘地区另一处古洋壳残片, 其时代比果干加 年山地区的堆晶辉长岩时代还要老 ${ }^{[6]}$, 这也是芫塘中 央隆起地区又一处早古生代蛇绿岩的残片, 同时也 说明㒸塘中央隆起带记录了特提斯洋不同时期演化
的历史的信息.

\section{2 地质意义}

芫塘地区是否存在蛇绿岩长期以来存在较大争 论 $^{[1,2,3 \sim 5]}$, 近年的区调和研究工作先后报道了典型大 洋中脊型基性岩类的存在, 并做了初步研究 ${ }^{[6 \sim 10]}$, 证 明蛇绿混杂岩的存在. 桃形湖变质基性岩呈岩块、岩 片状产出, 主要由变质超基性岩、变质堆晶辉长岩、 变质辉长岩(辉绿岩)、变质玄武岩和斜长花岗岩(斜长 岩)等组成, 局部地方破碎较强, 显示其经历了较强 的构造运动, 各类岩石之间除局部见有后期辉绿岩 岩墙侵入, 以及斜长花岗岩(斜长岩)与堆晶辉长岩的 接触关系外, 其它岩石之间的接触关系不太清晰. 变 质基性岩地球化学特征具有大洋中脊玄武岩类似的 特征, 并可能具有岛弧岩浆活动的亲缘性, 这与果干 加年山地区的变质基性岩有相似之处也有区别 ${ }^{[9]}$, 但 它们均属于蛇绿岩的成分. 变质堆晶辉长岩锆石 ${ }^{176} \mathrm{Hf} /{ }^{177} \mathrm{Hf}$ 在 $0.282615 \sim 0.282657$ 之间, $\varepsilon_{\mathrm{Hf}}(t)$ 加权平均 值为 $5.02 \pm 0.28$, 表明其岩浆来源于亏损型地幔 ${ }^{[24]}$. 此外, 此处还报道有蓝片岩 ${ }^{[25,26]}$, 因此, 桃形湖地区 的这套变质基性岩很可能是一个由构造作用堆积在 一起的混杂体, 而变质基性岩地球化学成分具有大 洋中脊玄武岩的特征, 它可能是被肢解的蛇绿岩成 分, 代表古洋壳的残片. 桃形湖与果干加年山地区的

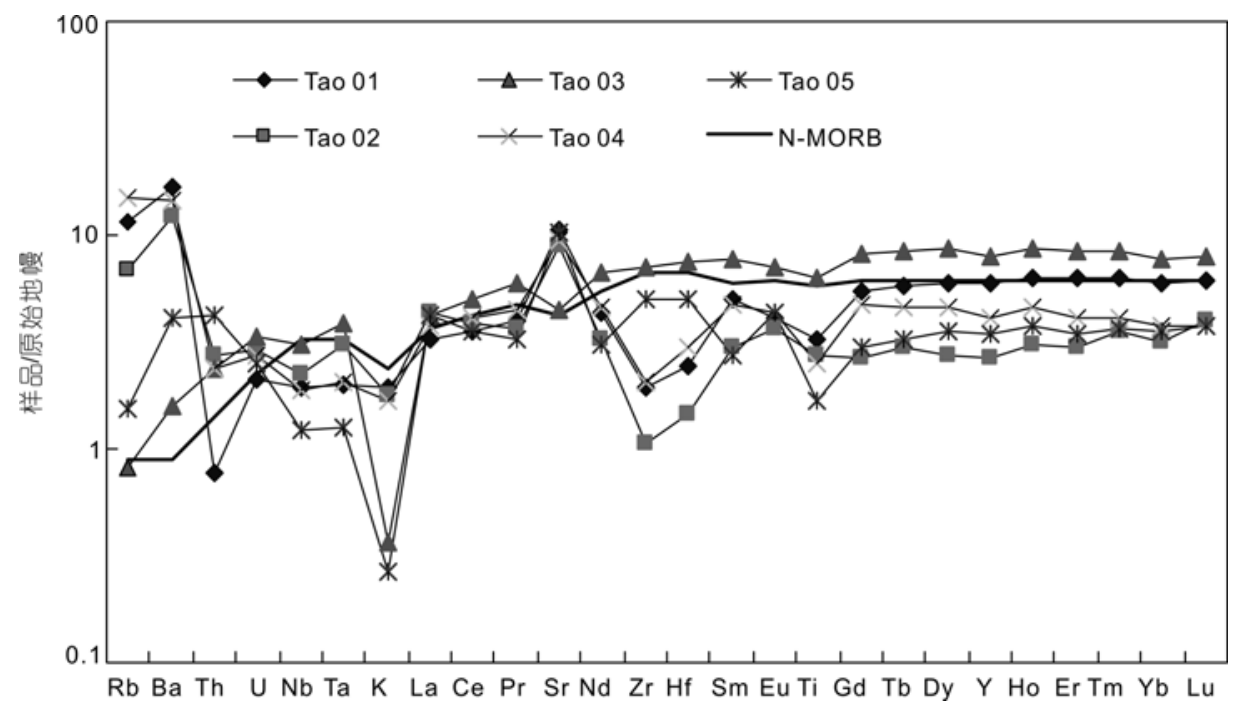

图 7 藏北㒸塘桃形湖地区变质基性岩微量元素比值蛛网图

原始地幔和 N-MORB 数据数据见文献[23] 
具有大洋中脊玄武岩特征的变质基性岩, 是西藏内 部早古生代特提斯洋演化的记录.

㒸塘地区是否存在古老基底长期以来一直存在 争论 ${ }^{[10,12,27]}$, 根据现有资料, 芫塘地区有可靠化石资 料的最老地层为中奥陶世 ${ }^{[28]}$, 对于是否存在更老岩 石，尚缺少生物化石和年龄资料. 桃形湖变质堆晶辉 长岩是目前㒸塘地区最老、最可靠的岩浆岩年龄. 堆 晶辉长岩一般形成于稳定的大陆内部或大洋(蛇绿岩 成分), 桃形湖变质堆晶岩具有与大洋中脊玄武岩类
似的特征，它很可能代表古洋壳的残片，但不论它是 是否为蛇绿岩以及形成于哪种构造环境都给我们一 个启示，芫塘地区很可能存在中奥陶世之前的岩石. 最近我们在㒸塘地区发现了中奥陶世花岗片麻岩(翟 庆国等另文发表), 岩石侵位于中央隆起地区的“浅变 质岩”中，说明这套“浅变质岩”时代应老于中奥陶世， 与本文获得的启示相一致. 㒸塘中央隆起地区肯定 存在前奥陶世岩石，只是目前研究程度不够，没有发 现而已.

致谢锆石样品制备、阴极发光照相和 SHRIMP 分析得到了北京离子探针中心刘敦一、陶华、杨之青、周惠等老 师帮助, 主量元素和锆石 Hf 同位素分析得到了中国科学院地质与地球物理研究所李禾和杨岳衡等的帮助, 在此一并致以衰心的感谢.

\section{参考文献}

1 李才. 龙木错-双湖-澜沧江板块缝合带与石炭二叠纪冈瓦纳北界. 长春地质学院学报, 1987, 17: 155-166

2 李才, 程立人, 胡克, 等. 西藏龙木错-双湖古特提斯缝合带研究. 北京: 地质出版社, 1995

3 王成善, 胡承祖, 吴瑞忠, 等. 西藏北部查桑-茶布裂谷的发现及其地质意义. 成都地质学院学报, 1987, 14: 33-46

4 邓万明, 尹集祥, 呙中平. 姜塘茶布-双湖地区基性超基性岩、火山岩研究. 中国科学 D 辑: 地球科学, 1996, 26: 296-301

5 尹集祥. 青藏高原及邻区冈瓦纳相地层地质学. 北京: 地质出版社, 1997

6 李才, 董永胜, 翟庆国, 等. 青藏高原芫塘早古生代蛇绿岩一一堆晶辉长岩的铅石 SHRIMP 定年及其意义. 岩石学报, 2008, 24: 3136

7 翟庆国, 李才, 程立人, 等. 西藏芫塘角木日地区二叠纪蛇绿岩地质特征及构造意义. 地质通报, 2004, 23: 1228一-1230

8 翟庆国, 李才, 黄小鹏. 西藏美塘角木日地区二叠纪玄武岩地球化学特征及构造意义. 地质通报, 2006, 25: 1419-1427

9 翟庆国, 李才, 黄小鹏. 西藏差塘中部古特提斯洋残片一一来自果干加年山变质基性岩地球化学证据. 中国科学 D 辑: 地球科学, 2007, 37: 866-872

10 李才. 芫塘基底质疑. 地质论评, 2003, 49: 5-9

11 西藏地质矿产局. 西藏自治区区域地质志. 北京: 地质出版社, 1993

12 王国芝, 王成善. 西藏芫塘基底变质岩系的解体和时代厘定. 中国科学 D 辑: 地球科学, 2001, 31(增刊): 77一82

13 Claoue-Long J C, Compston J, Roberts C M, et al. Two Carboniferous ages: A comparison of SHRIMP zircon dating with conventional zircon ages and ${ }^{40} \mathrm{Ar} /{ }^{39} \mathrm{Ar}$ analysis. In: Geochronology Time Scales and Global Stratigraphic Correlation 54. SEPM Special Publication, 1995. 3-21

14 Williams I S, Claesson S. Isotope evidence for the Precambrian province and Caledonian metamorphism of high grade paragneiss from the Seve Nappes, Scandinavian Caledonides, II . Ion microprobe zircon U-Th-Pb. Contrib Mineral Petrol, 1987, 97: 205-217

15 Ludwig K R. Squid1.02: A User Manual. Berkeley Geochronogical Center Special Publication, 2001. 219

16 Ludwig K R. Using Isoplot/EX, Version 2, A Geochronological Toolkit for Microsoft Excel. Berkeley Geochronogical Center Special Publication, 1999. 47

17 Steiger R H, Jager E. Subcommission on geochronology: Convetion or the use of decay constants in geo- and cosmo-chronology. Earth Planet Sci Lett, 1997, 36: 359-362

18 Compston W, Williams I S, Mayer C. U-Pb geochronology of zircons from Lunar Breccia 73217 using a Sensitive High Resolution Ion Microprobe, Proc. XIV Lunar Planetary Science Conference. J Geophys Res, 1984, 89(Suppl): B525—534

19 Wu F Y, Yang J H, Xie L W, et al., Hf isotopic compositions of the standard zircons and baddeleyites used in U-Pb geochronology. Chem Geol, 2006, 234: 105-126

20 Woodhead J, Hergt J, Shelley M, et al. Zircon Hf-isotope analysis with an excimer laser, depth profiling, ablation of complex geonmetries and concomitant age estimation. Chem Geol, 2004, 209: 121-135

21 Han Y G, Zhang S H, Pirajno F, et al. Evolution of the Mesozoic granites in the Xiong'ershan-Waifangshan region, western Henan Province, 
22 Hoskin P W O, Black L P. Metamorphic zircon formation by solid-state recrystallization of protolith igneous zircon. J Metamorph Geol, 2000, 18: 423-439

23 Sun S S, McDonough W F. Chemical and isotopic systematics of oceanic basalt: implications for mantle composition and processes. In: Saunders A D, Norry M J, eds. Magmatism in the Ocean Basins. London Geol Soc Spec Pub, 1989, 42: 528—548

24 吴福元, 李献华, 郑永飞, 等. Lu-Hf 同位素体系及其岩石学应用. 岩石学报, 2007, 23: 185-220

25 邓希光, 丁林, 刘小汉, 等. 藏北㒸塘中部冈玛日-桃形错蓝片岩的发现. 地质科学, 2000, 35: 227一232

26 Kapp P, Yin An, Manning C E, et al. Blueschist-bearing metamorphic core complexes in Qiangtang block reveal deep crustal strusture of northern Tibet. Geology, 2000, 28: 19-22

27 王成善, 伊海生, 李勇, 等. 西藏差塘盆地地质演化与油气远景评价. 北京: 地质出版社, 2001. 1-59

28 李才, 程立人, 张以春, 等. 西藏㒸塘南部发现奥陶纪-泥盆纪地层. 地质通报, 2004, 23: 602-604 